Received 00th January 20xx, Accepted 00th January 20xx DOI: $10.1039 / \times 0 \times x 00000 x$

\title{
Plasma Production of Nanomaterials for Energy Storage: Continuous Gas-Phase Synthesis of Metal Oxide CNT Materials via a Microwave Plasma
}

\author{
Brian Graves ${ }^{a}$, Simon Engelke ${ }^{b, c}$, Changshin Jo ${ }^{b}$, Herme G. Baldovid, Jean de la Verpilliere ${ }^{a}$, Michael \\ De Volder ${ }^{\mathrm{b}}$, and Adam Boies ${ }^{\mathrm{a} *}$
}

\begin{abstract}
In this work we show for the first time that a continuous plasma process can synthesize materials from bulk industrial powders to produce hierarchical structures for energy storage applications. The plasma production process's unique advantages are that it is fast, inexpensive, and scalable due to its high energy density that enables low-cost precursors. The synthesized hierarchical material is comprised of iron oxide and aluminum oxide aggregate particles and carbon nanotubes grown in-situ from the iron particles. New aerosol-based methods were used for the first time on a battery material to characterize aggregate and primary particle morphologies, while showing good agreement with observations from TEM measurements. As an anode for lithium ion batteries, a reversible capacity of $870 \mathrm{mAh} / \mathrm{g}$ based on metal oxide mass was observed and the material showed good recovery from high rate cycling. The high rate of material synthesis ( $10 \mathrm{~s}$ residence time) enables this plasma hierarchical material synthesis platform to be optimized as a means for energetic material production for the global energy storage material supply chain.
\end{abstract}

\section{Introduction}

Traditional manufacturing techniques for energy storage materials are often slow and complex. Wet chemistry approaches can contain an extensive series of steps and regularly require hours or even days to execute. Moreover, many existing energy storage material synthesis processes begin with precursors that are challenging and costly to produce, such as nanoparticles or carbon nanotubes (CNTs). In particular, CNT synthesis is difficult because it requires high temperature as well as precise carbon input and catalyst preparation. It is also most often completed as a substratebased, batch process whereby additional steps are required to remove and purify the CNTs. Nevertheless, the use of structured combinations of nanomaterials within energy storage devices enables fast diffusion rates through high surface areas, control of crystal size, unique chemistries and structures that make simultaneous use of conductive and insulating materials. Unfortunately, given the added complexity of their fabrication, most processes that include nanomaterials such as CNTs in energy storage materials begin with those that are

\footnotetext{
a. Department of Engineering, University of Cambridge, Trumpington Street,

Cambridge, CB2 1PZ, United Kingdom.

b. Institute for Manufacturing, University of Cambridge, 17 Charles Babbage Road, Cambridge, CB3 OFS, United Kingdom

c. Cambridge Graphene Centre, University of Cambridge, $9 \mathrm{JJ}$ Thomson Avenue, Cambridge, CB3 OFA, United Kingdom

d. Department of Chemical Engineering and Biotechnology, University of Cambridge, Philippa Fawcett Drive, Cambridge, CB3 OAS, United Kingdom
}

Electronic Supplementary Information (ESI) available: Additional microscopy, detailed process schematic, and further electrochemical results. See DOI: $10.1039 / x 0 x \times 00000 x$ prefabricated. This multi-step supply chain places limits on the lower bound of the final product's price and may inhibit its widespread adoption in the consumer market.

Optimization of anode design for enhanced lithium ion batteries is paramount for automotive, electronic, and power storage applications since the anode is one of the primary drivers of the cell's total capacity, multi-cycle stability, as well as the maximum charge and discharge rates. Recent advancements in metal oxide conversion anodes have shown that higher capacities can be achieved for metal oxides, e.g. $926 \mathrm{mAh} / \mathrm{g}$ for $\mathrm{Fe}_{3} \mathrm{O}_{4}$ and $1008 \mathrm{mAh} / \mathrm{g}$ for $\mathrm{Fe}_{2} \mathrm{O}_{3}$, when compared to graphite and lithium titanium oxide which are $372 \mathrm{mAh} / \mathrm{g}$ and $175 \mathrm{mAh} / \mathrm{g}$ respectively. Moreover, metal oxides are not prone to the lithium dendrite formation which degrades graphite anode performance. Existing studies on metal oxide anodes has confirmed their effectiveness as a near drop-in replacement for convention lithium ion battery formulations with reported energy densities that can often be in excess of $800 \mathrm{mAh} / \mathrm{g}(1-7)$, though studies demonstrate that cyclability and voltage hysteresis remain challenging. Full cell LIBs with metal oxide anodes have been matched to numerous typical cathodic chemistries, including $\mathrm{LiCoO}_{2}(8)$ and $\mathrm{LiFePO}_{4}(9,10)$ and have achieved full cell capacities of $360 \mathrm{mAh} / \mathrm{g}(10)$ to $400 \mathrm{mAh} / \mathrm{g}(8)$. Metals such as iron have already attracted interest from industry.(11) Despite exhibiting multiple improvements over graphitic anodes, metal oxide anodes originally had limited use due to the volume expansion and contraction experienced during a charge/discharge cycle. More recent work has shown that reduction in particle size and the incorporation of 
conductive and stabilizing elements (such as carbon coatings or CNTs) can dramatically reduce this effect. $(5,7)$

The morphology of multiple carbon nanotubes grown radially from a nanoparticle surface (known informally as carbon nanotube sea urchins) was described in a form most similar to the work presented here by Kim et al.(12) and by De La Verpilliere et al.(13). Sea urchins are formed from bi-metallic cores containing catalyst and non-catalyst metals, in this case iron and aluminum respectively. Within the nanoparticle core, islands of reduced metal exist within an aluminum or iron/aluminum alloy matrix. These catalyst sites grow CNTs (as seen in Figure 1a) and can be present in tens and even hundreds across the surface of a given core particle. Morphologies similar to the sea urchins have been used in CNT/metal oxide energy storage, including anodes. Collections of metal oxide subunits such as nanoparticles and nanorods mixed with CNTs have proven to be effective anodes (Figure $1 b-d) .(1,2,7)$ Additionally, material morphologies have been reported which contain metal oxides mixed with CNTs to form larger structural units such as spheres or polyhedra (Figure 1e-g). $(3-5,14)$ The presence of CNTs in these hybrid materials has been shown to reduce electrode pulverization and increase electron conductivity, resulting in improved capacity and fast charge-discharge rate performance. $(3,5,7,14)$ Inversed geometries have also been studied, where anode materials have been produced from of CNTs coated in metal oxide nanoparticles (Figure 1h), with single component transition metals $(6,15-21)$ as well as bimetallic systems(22-25).

While these hierarchical structures have shown great benefit as anode materials, many of the approaches are not scalable, using expensive or prefabricated materials with complex, time consuming, multi-step processes. This study's process (Figure $1 \mathrm{i}$, explained in detail in the methods section) utilizes a high temperature $(>2500 \mathrm{~K}$ ) microwave plasma CVD process, which enables the use of inexpensive and readily available raw materials (iron and aluminum powder) and results in a residence time of approximately ten seconds. The resulting material has hierarchical structure consisting of a core iron and aluminum oxide nanoparticles encapsulated with a carbon coating and multiple CNTs (Figure $1 \mathrm{j}$ ). The highly conductive carbon coatings and CNTs negate the need for post process conductive additives during anode assembly. Thermal plasma processes are often used industrially for large-scale production of nanopowders including metals and ceramics.(26) Synthesis of high-value carbonaceous products such as CNTs(27-30) has also been reported at rates up to $100 \mathrm{~g} / \mathrm{h}(29)$. The energy density of a plasma can be two orders of magnitude larger than that of a furnace, allowing large mass throughputs from comparatively small systems. However, this high energy density and the fast kinetics within thermal plasmas have historically limited their use in creating designed multi-component nanostructures.

In this work we show for the first time that hierarchical energy storage materials can be produced in a single-step process. These materials are produced efficiently from bulk industrial powders in a fast, simple, and scalable plasma-based process. The resulting plasma synthesized metal oxide-CNT materials are characterized using on-line techniques that give real-time morphology metrics of the synthesized materials, allowing for real-time process optimization. The hybrid anodic materials produced in a single-step are collected, processed and analyzed within half-cell devices to determine the cycling capability of the synthesized materials. 


\section{Results and Discussion}

The hierarchical structure of the metal oxide-CNT material is shown in Figure 2a. Metal oxide primary particles (iron and aluminum) on the order of nanometres to tens of nanometres comprise larger fractal-like aggregate particles (I) which are several tens to several hundreds of nanometres across. Primary particles are coated with graphitic carbon (II) and catalyse CNT growth (III). Primary particles can often be seen trapped within the CNT (IV), separate from their host aggregate as depicted in Figure $2 \mathrm{~b}$ (microscopy details in methods section). The aggregate particles and CNTs agglomerate further as they deposit on the collection filter, resulting in a final material formed of a continuous matrix of metal oxide particles and CNTs as shown in Figure 2c. The carbonaceous coating on the particles shown in Figure $2 d$ increases the short-range electrical conductivity of the material (i.e. between primary particles of a given aggregate). The multilayer graphitic structure is shown to encapsulate most primary particles providing intra-aggregate

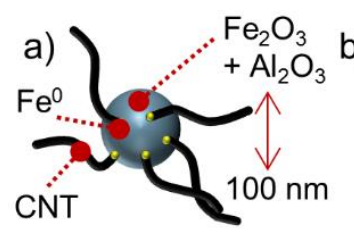

e)
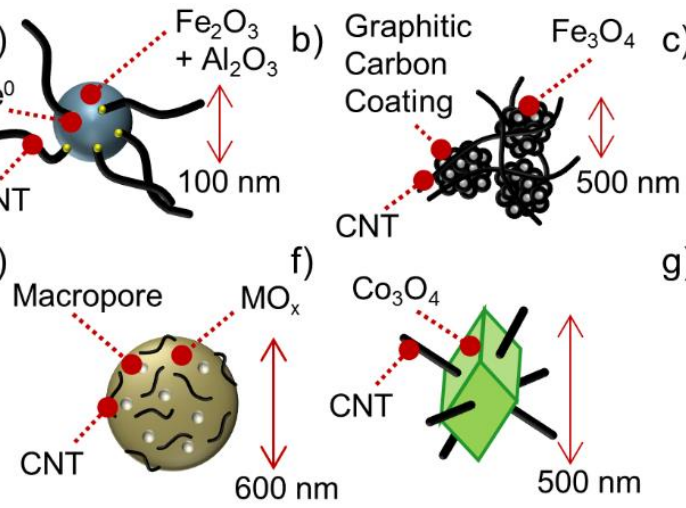

g)
$500 \mathrm{~nm}$ conductivity. The CNTs that grow from the fractal aggregate surface are tens of micrometres long and allow contact between aggregate particles for inter-aggregate conduction. Carbonaceous components in anodes including coatings and CNTs have repeatedly been shown to increase conductivity and improve battery performance.(31) As a result, anode construction is simplified since no conductive additive is necessary. In addition, carbon conformally bonded to the metal oxide provides more efficient electron conduction compared with an externally-mixed conductive additive such as super $P$ since the super $\mathrm{P}$ conducts electricity via point contact between the super $P$ particles and metal oxide particles. Iron and aluminum serve as useful metals for this process since iron is a catalyst for CNT growth and multiple forms of iron oxide are excellent candidates for lithium ion anodes.

\section{Aggregate Size Distribution}

On-line scanning mobility particle spectrometer (SMPS) measurements of the aggregate core particles measured at the

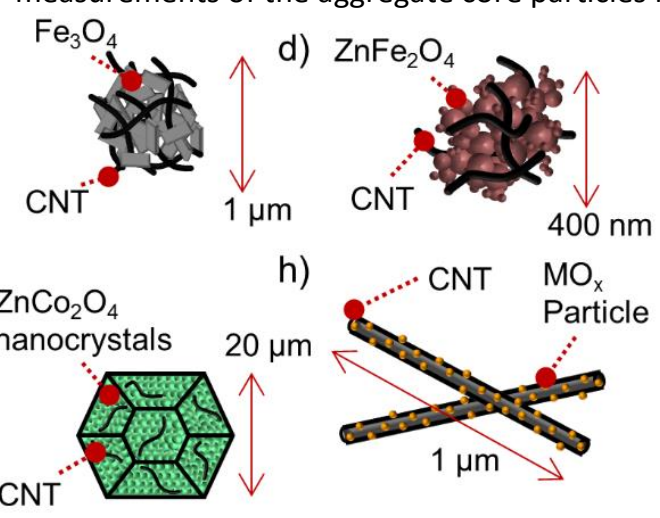

i)

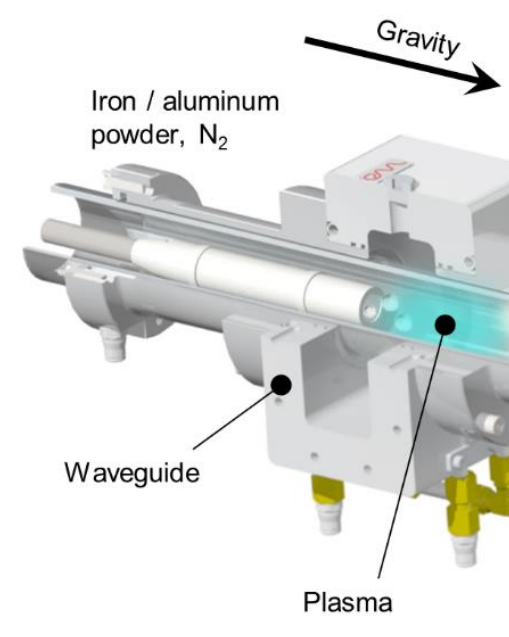

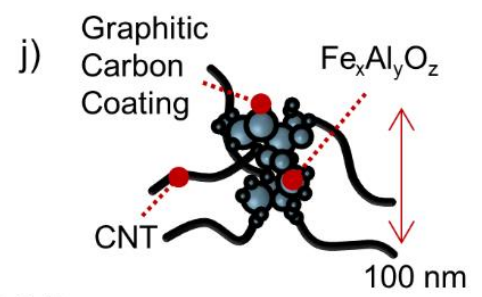

Nanoparticle renucleation and agglomeration

$\mathrm{H}_{2}+\mathrm{C}_{2} \mathrm{H}_{2}$ introduction

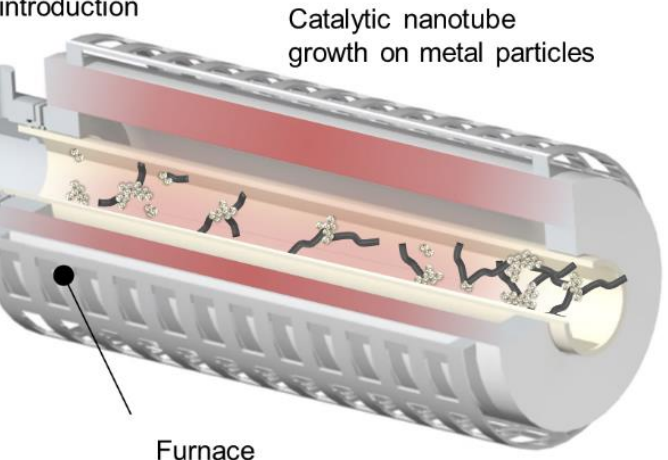

Figure 1: Previously synthesized hybrid CNT architectures for energy storage (a-h), where (a) is the existing "sea urchin" mophology $(12,13),(b) \mathrm{Fe}_{3} \mathrm{O}_{4}$ crystals coated in carbon and mixed with CNTs(2), (c) $\mathrm{Fe}_{3} \mathrm{O}_{4}$ nanorods embedded in a CNT web(1), (d) $\mathrm{ZnFe}_{2} \mathrm{O}_{4}$ particles aggregated with CNTs(7), (e) CNTs encapsulated in porous or nonporous $\mathrm{SnO}_{2}$ or $\mathrm{MnO}$ spheres(3,5), (f) $\mathrm{Co}_{3} \mathrm{O}_{4}$ polyhedra grown on a CNT network(4), (g) $\mathrm{ZnCo}_{2} \mathrm{O}_{4}$ nanocrystals assembled into polyhedra and mixed with CNTs(14), and (h) CNTs decorated with metal oxide nanoparticles(6,15-25). (i) depicts our high throughput plasma anode material production, with (j) material schematic of the $\mathrm{Fe}_{x} \mathrm{Al}_{y} \mathrm{O}_{z}$ core with graphitic coating and surface CNTs. 
exit of the plasma system as well as the cores after CNT growth in the furnace are presented in Figure 3a, and provide real-time size distribution data for the system (see methods). The mobility diameter $d_{\mathrm{m}}$ represents the diameter of a sphere with the same drag as the measured irregular aggregate particles. The number concentration $N$ is normalized by logarithmically spaced size bin width as $\mathrm{d} N / \mathrm{d} \log d_{\mathrm{m}}$. The increase in particle size due to the growth of CNTs is represented by the shift in the geometric mean diameter (GMD) from $41 \mathrm{~nm}$ for aggregated core particles to $157 \mathrm{~nm}$ after CNT growth. The measurement and counting of each particle within the distribution $\left(>10^{6}\right.$ particles measured per scan) gives detailed statistical information not readily available from microscopy. The geometric standard deviation $\left(\sigma_{\mathrm{g}}\right)$ of the particles is 1.87 and 1.94 before and after growth, and given more time would decrease according to theoretical and other experimental predictions $\left(\sigma_{\mathrm{g}} \sim 1.45\right)$ for gas-phase nanoparticles undergoing agglomeration.(32) Particles continue to agglomerate and are lost to the wall by thermophoretic and diffusive forces to the reactor walls during the growth stage. The reactor number concentration of particles reduced from $2.18 \times 10^{8} \mathrm{~cm}^{-3}$ before the furnace to $6.66 \times 10^{7} \mathrm{~cm}^{-3}$ after the furnace.

\section{Mass Mobility Relation and Primary Particle Size}

While size-based particle information contributes to a partial understanding of morphology, further details can be gleaned by combining size data with mass measurements. The relation between the mobility-equivalent diameter and mass for aggregates has the form

$$
m=C d_{\mathrm{m}}^{{ }^{D_{\mathrm{m}}}} .
$$

Here, $m$ is aggregate particle mass, $C$ is a constant prefactor, and $D_{\mathrm{m}}$ is the mass-mobility exponent. For a spherical particle (i.e. a liquid droplet) $D_{\mathrm{m}}$ is 3 , thus the particle's mass scales with diameter cubed and $C$ is a function of the material density, $m_{\mathrm{s}}=(\rho \pi / 6) d_{s}{ }^{3}$. For a two-dimensional object such as a sheet (i.e. graphene) the mass mobility exponent will be 2 and for a one-dimensional object (CNT) $D_{\mathrm{m}}$ will be 1 . Fractal-like aggregates such as those produced here (as in most noncoalescing aerosol processes) possess mass-mobility exponents between 2 and 3 since they grow in three dimensions but do no not completely fill a given spherical volume. Mass-mobility exponents where $D_{\mathrm{m}} \rightarrow 3$ represent compact aggregates whereas when $D_{\mathrm{m}} \rightarrow 2$ the aggregates containing more branching and open space, increasing the exposed surface area, as depicted in Figure $3 b$.

The individual particle masses and mobility diameters were measured in series at the plasma exit, and the mass-mobility relation is plotted in Figure $3 \mathrm{c}$ to provide structural information of the core particles. The power-law fit to the particles measured at many different mobility diameters results in $D_{\mathrm{m}}=$ a)

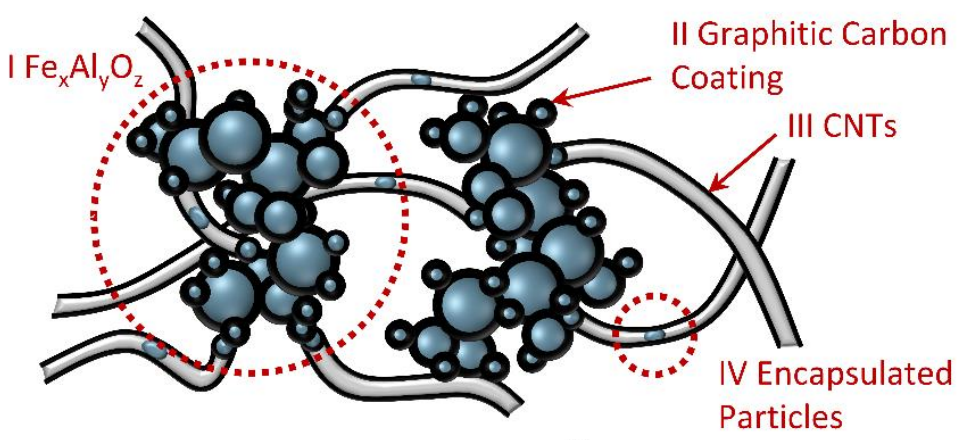

c)

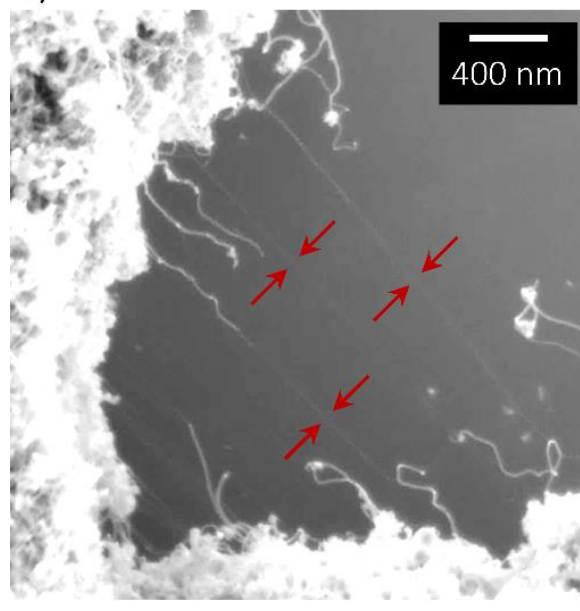

d)

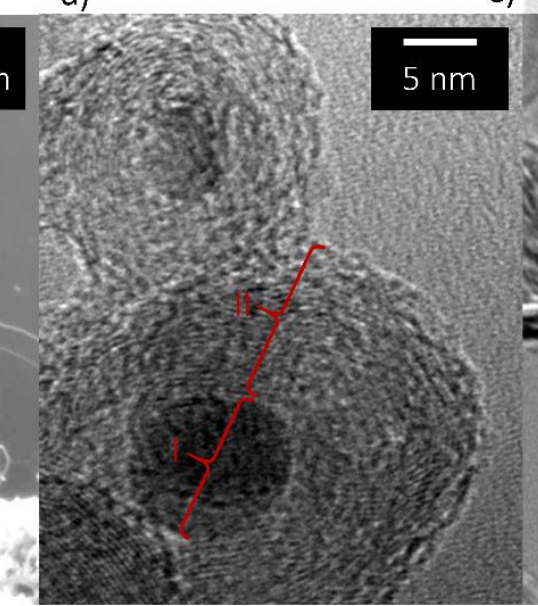

b)

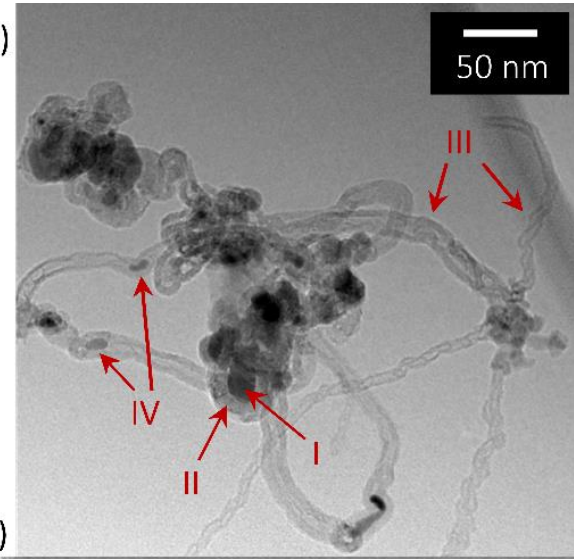

e)

Figure 2: Hierarchical metal oxide-CNT (a) material schematic and images including (b) TEM of individual aggregate, (c) SEM of bulk material, (d) TEM of primary particle and carbon coating, and (e) single CNT cross-section. Additional images available in the supporting information 
2.31. These results are similar to flame-synthesized oxide particles such as zirconium oxide(33) and silica(34), as well as metals from spark discharge synthesis including gold(35) and copper(36). Further, mass-mobility measurements of aggregate particles can also be used to estimate the diameter of primary particles within an aggregate as well as the number of primaries per aggregate. Primary particles may be of particular importance since this functional unit dictates the surface area to volume ratio of the active material. Smaller particles will have most of their mass within several nanometers of the surface which can facilitate lithiation and delithiation processes (and should be less susceptible to pulverization), however smaller primary particles may also be more prone to SEI formation, as their higher specific surface area provides more opportunity for electrolyte breakdown(37). Primary particle diameter can be estimated using the formulas developed by Eggersdorfer et al.(33), and this technique is explained in detail in the methods section.

Figure $3 \mathrm{~d}$ shows that the metal oxide aggregates synthesized from the plasma system contain primary particles of diameter ranging from approximately $d_{\mathrm{pp}}=9 \mathrm{~nm}$ to $19 \mathrm{~nm}$, with a small positive correlation between mobility diameter and primary particle diameter. Differences in primary particle diameters result from unique time-temperature profiles of the primary particles in the reactor. Higher concentration of metal vapour results in saturation at higher temperatures, thus allowing coalescing growth from coagulation. The increase in primary particle number with aggregate size is shown in Figure 3e, whereby approximately nine particles are contained in a $30 \mathrm{~nm}$ aggregate and increases to several hundred particles are contained within a $200 \mathrm{~nm}$ aggregate. The aggregate size, surface area and primary particle numbers can be measured in a)

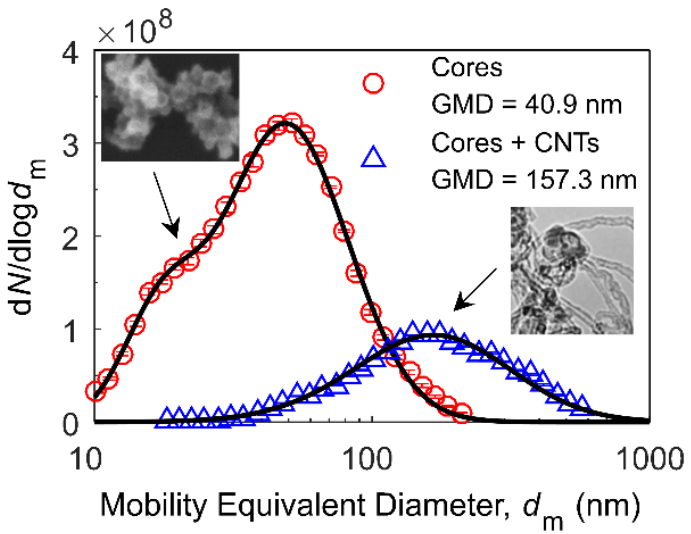

c)

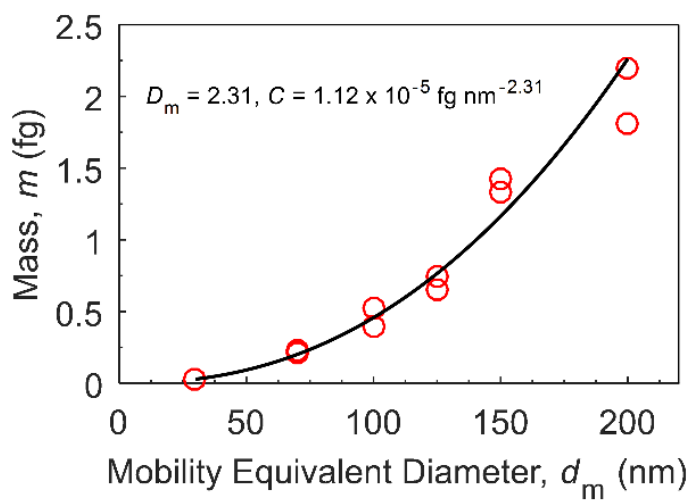

e)

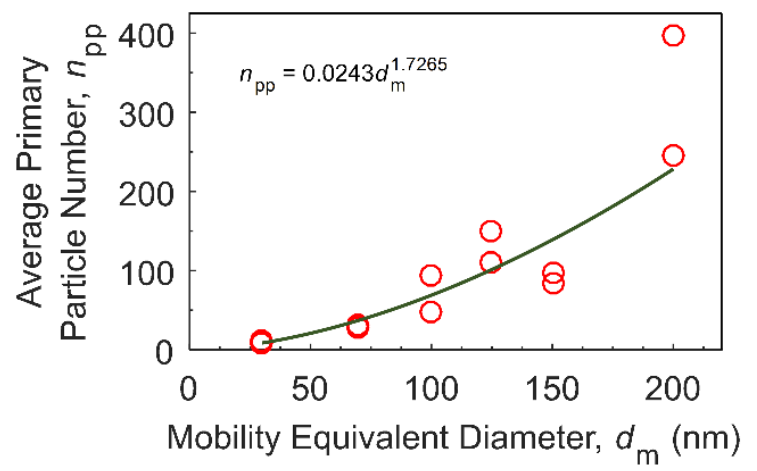

b)

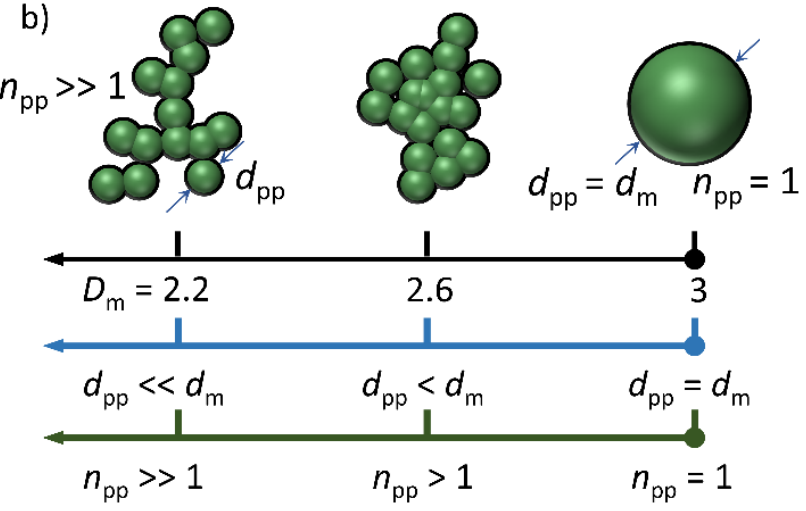

d)

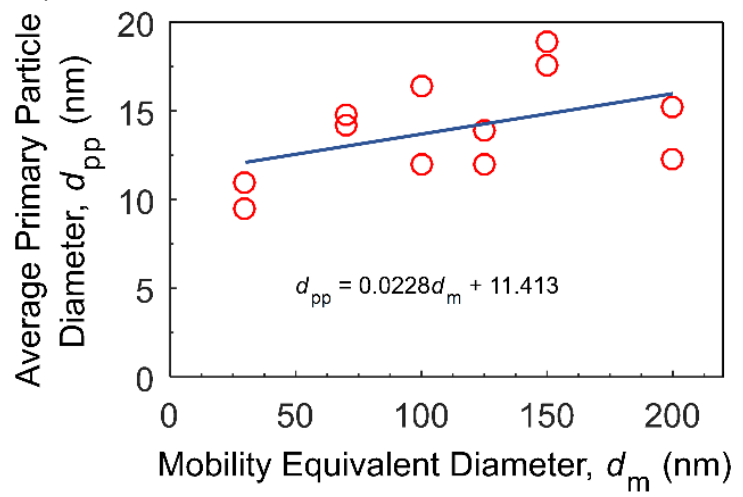

f)

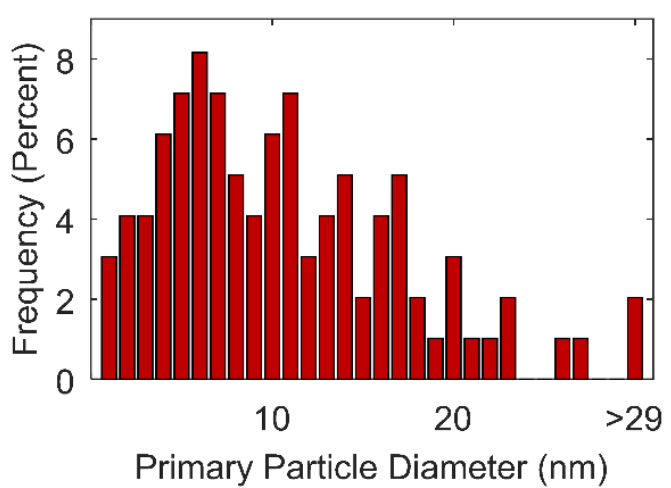

Figure 3: (a) SMPS scans of core particles after plasma and cores plus CNTs after growth. Five scans were performed for each condition. Error bars represent one standard deviation, (b) schematic of particles associated with various mass-mobility exponents (c) mass-mobility relation for metal oxide core particles, (d) average primary particle diameter, (e) average primary particle number per aggregate, and (f) histogram of primary particle size from TEM 
real time from the process and monitored relative to the influence on the rates of lithium diffusion and SEI formation. The mean population primary particle was $13.4 \mathrm{~nm}$ for those conditions that resulted in the best battery performance measured in this study (see methods).

The distribution of primary particle size as measured from TEM is shown in Figure 3f. Statistical analysis of the primary particle size distribution from TEM resulted in an average primary particle diameter of $11.28 \pm 6.85 \mathrm{~nm}$, which agrees well with the results of the aerosol-based method. As such, estimation of primary particle size and number through the aerosol-based method is a desirable alternative to TEM since it is a statistically

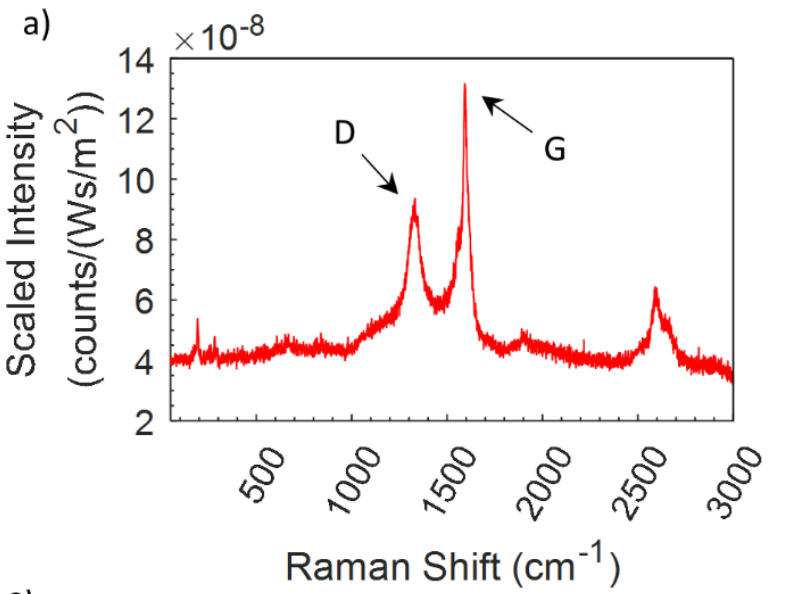

c)

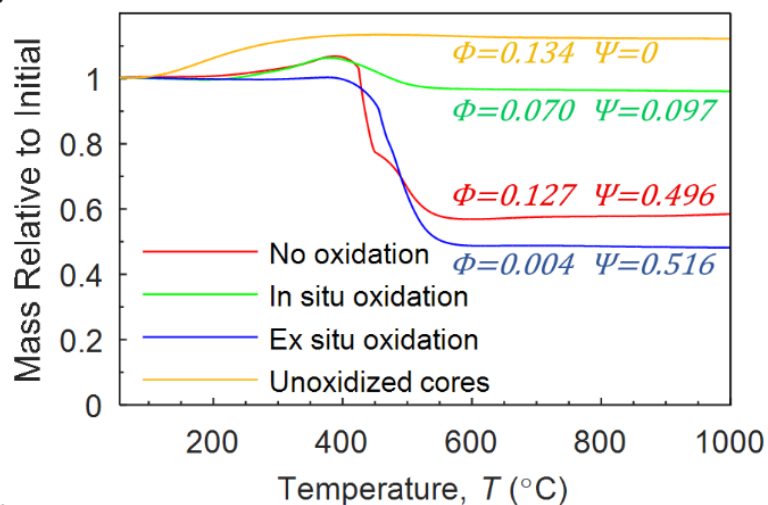

e)

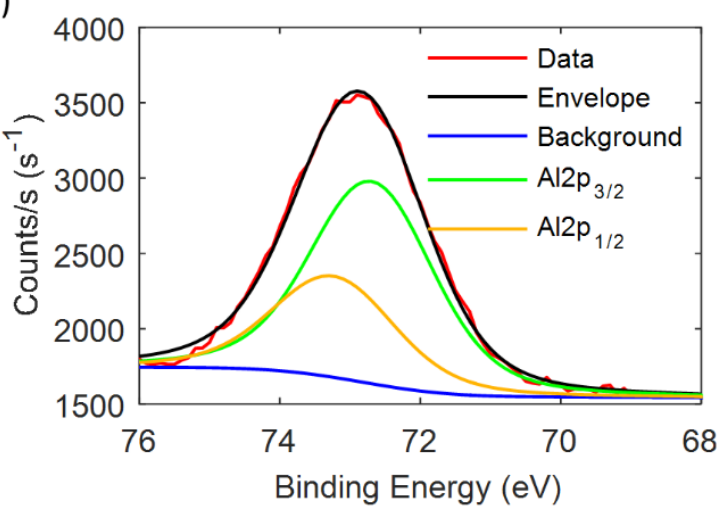

robust method in which $\sim 10^{6}$ particles are measured and represented by each data point. The total mass production of material was determined from the combined SMPS and CPMA measurement (see methods). Using the mass-mobility exponent and prefactor from Figure $3 \mathrm{c}$ of 2.31 and $1.12 \times 10^{-5} \mathrm{fg}$ $\mathrm{nm}^{-2.31}$ respectively, the total mass concentration of core material is $30.73 \mathrm{mg} / \mathrm{m}^{3}$. Given the total flow rate of gas through the plasma system of $9 \mathrm{slpm}$, the production rate of cores in this study's configuration is $16.6 \mathrm{mg} / \mathrm{h}$ (and approximately $33 \mathrm{mg} / \mathrm{h}$ for cores and CNTs given that the core mass fraction is $\sim 50 \%)$. While material yield was not optimized for this study, optimizations that increase the powder feed through the plasma and reduce deposition losses on the tube

Nanotube Diameter $(\mathrm{nm})$

b) $\begin{array}{lllll}2.0 & 1.5 & 1.0 & 0.8 & 0.7\end{array}$

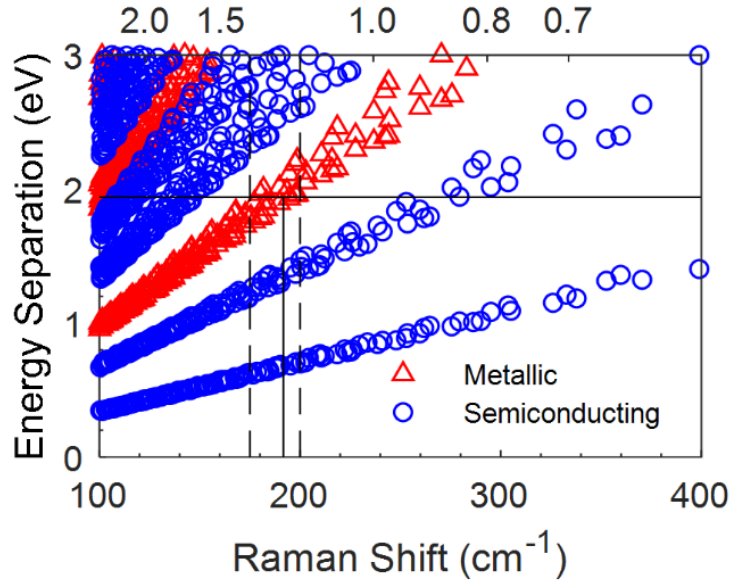

d)

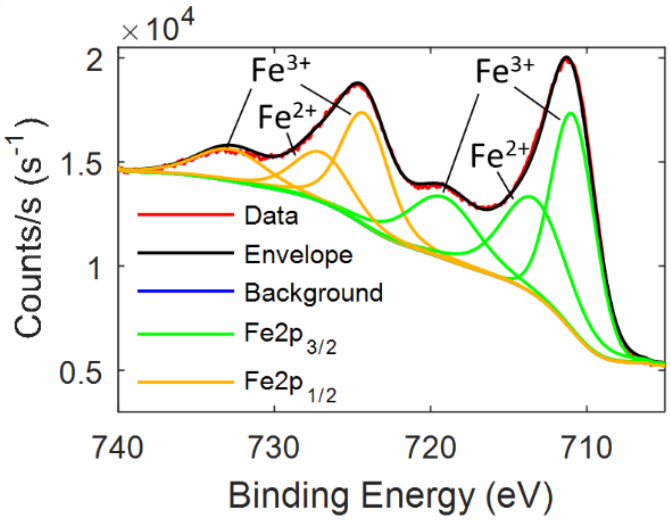

f)

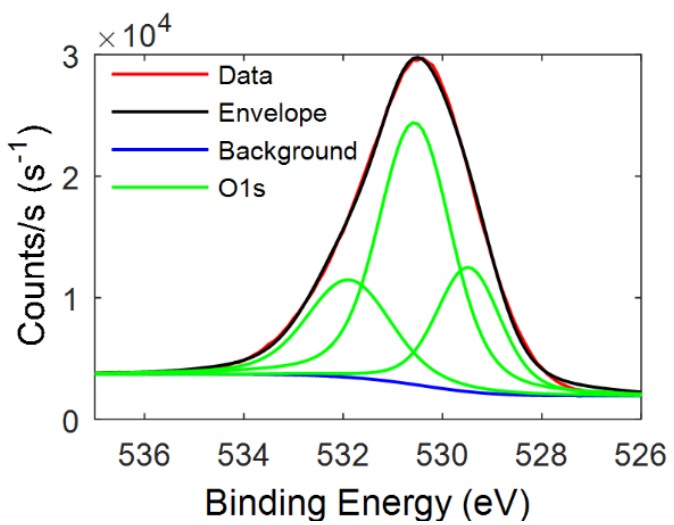

Figure 4: (a) Raman spectrum of CNT/metal oxide composite material, (b) Kataura plot using RBM from Raman, (c) TGA of metal oxides and CNTs with various process modifications, where $\Phi$ is the uptake mass of oxygen during TGA relative to the initial metal oxide mass and $\psi$ is the mass fraction of CNTs to total product mass, (d) XPS data and curve fit for iron, (e) aluminum, and (f) oxygen 
walls would allow orders of magnitude higher production. The theoretical upper limit to mass throughput if $50 \%$ of the plasma power used in this work is dedicated to heating and vaporizing the powder mixture from room temperature to the vaporization point of iron $\left(>2861^{\circ} \mathrm{C}\right), 1.15 \mathrm{~kg} / \mathrm{h}$ can be processed, indicating that even a lab-scale plasma system is capable of impressive production rates.

\section{CNT Characterization}

From TEM, it is evident that there is a range in CNT diameter, as shown in Figure $2 \mathrm{~b}$. On average, the CNTs have a diameter of $7.75 \pm 2.74 \mathrm{~nm}$ with six to seven walls (see supporting information for additional statistics on CNTs and primary particles). A single CNT cross-section is displayed in

Figure $2 \mathrm{e}$ where the expected wall spacing of $0.34 \mathrm{~nm}(38)$ is clearly visible. CNTs were predominantly observed growing from particles $6 \mathrm{~nm}$ and smaller. These particles often detached themselves from their host aggregate and were ultimately contained within the CNT growing from them. This phenomenon is demonstrated in Figure $2 \mathrm{~b}$. Particles larger than $6 \mathrm{~nm}$ were often coated in layers of carbon (see Figure 2d), most of which is crystalline although some amorphous carbon is present as well.

Raman spectra excited at $638 \mathrm{~nm}$ for the final material is shown in Figure 4a. The G/D ratio of the carbon coating and CNTs is approximately 1.8 . The majority of the signal from the $D$ peak is likely due to any amorphous carbon coating the larger primary particles. A radial breathing mode (RBM) at $191.7 \mathrm{~cm}^{-1}$ is also visible, indicating the presence of at least a few single-walled CNTs (SWNTs). From the Kataura plot in Figure 4b, properties of single-walled CNTs can be determined from the RBMs. The excitement energy of $1.943 \mathrm{eV}$ from the $638 \mathrm{~nm}$ laser can be intersected with the RBM wavenumber which shows that the peak corresponds to metallic CNTs. While other single-walled CNTs may exist which are not resonant with the $638 \mathrm{~nm}$ laser (see methods section), the fact that these single-walled CNTs are metallic means they will be good conductors between metal oxide cores. Given the non-discreet resonance curve of SWNTs to a given laser wavelength, as well as the continued uncertainty in the coefficients used to convert between wavenumber and diameter $(39,40)$, it is not feasible to match RBM peaks to specific data points/chiralities on the Kataura plot. Nevertheless, a diameter range can be extracted for these CNTs: the metallic CNTs have diameters between 1.21 and 1.39 $\mathrm{nm}$.

\section{Core Particle Composition and CNT mass fraction}

As an anode in a lithium ion battery, the metal oxide particles undergo a conversion reaction as they are charged and discharged with lithium ions. This global reaction for the lithium conversion reaction process is $\mathrm{M}_{x} \mathrm{O}_{y}+2 y \mathrm{e}^{-}+2 y \mathrm{Li}^{+} \rightleftarrows$ $x \mathrm{M}^{0}+y \mathrm{Li}_{2} \mathrm{O}$, where $\mathrm{M}$ represents a transition metal, in this case iron. To maximize energy density of metal oxide materials, high oxygen states are required. For aluminum, the most thermodynamically stable oxide is alumina, $\mathrm{Al}_{2} \mathrm{O}_{3}$, whereas multiple stable oxidation states exist for iron, including $\mathrm{FeO}$ (1 $\mathrm{O}: 1 \mathrm{Fe}), \mathrm{Fe}_{3} \mathrm{O}_{4}(1.33 \mathrm{O}: 1 \mathrm{Fe})$, and $\mathrm{Fe}_{2} \mathrm{O}_{3}(1.5 \mathrm{O}: 1 \mathrm{Fe})$.

Sample oxidation was studied using several methods. Concurrent oxygen gas $(0-15 \mathrm{sccm})$ injection with the nitrogen in the plasma (in-situ oxidation) showed insufficient oxidation of metals and increases in oxygen concentration competed with CNT growth. Decoupled CNT growth and core oxidation proved more effective, achieving near full oxidation of the metallic components. Plasma-produced unoxidized core particles with CNTs were collected. The resulting powder was then placed in an oxidation furnace at $300^{\circ} \mathrm{C}$ for one hour for ex-situ annealing. Figure $4 \mathrm{c}$ displays thermogravimetric analysis (TGA) characterizations of the material before and after oxidation, including in-situ oxidation and a base-case analysis using only unoxidized core particles without CNT growth. $\Phi$ represents the uptake mass of oxygen during TGA relative to the initial metal oxide mass and $\Psi$ represents the mass fraction of CNTs to total product mass. The unoxidized cores demonstrates that oxidation is completed at a lower temperature than the start of carbon combustion so these two processes can be independently quantified from TGA. Figure 4c demonstrates that the unoxidized core-only (no CNTs) material appears to gain a higher percentage of mass during TGA than other samples, but in absolute terms the increased oxidation of solely the metal is determined accounting for the non-metal fraction of material.

It is evident that without any added oxygen, the "no oxidation" and unoxidized core samples show the largest increase in mass during TGA with $\Phi$ equal to 0.127 and 0.134 , respectively. When an oxidation step is included, the material is seen to uptake less oxygen during TGA. In-situ oxidation (15 sccm $\mathrm{O}_{2}$ added to plasma) did improve core oxidation $(\Phi=0.070)$; however there is a dramatic decrease in CNT mass fraction as well $(\Psi=0.097)$. Since oxygen is required for core oxidation but a lack of oxygen is necessary for CNT growth, oxygen must be added subsequent to the CNT growth and can also be done in-situ with larger residence times. The separation of CNT growth and core oxidation steps resulted in material that is optimized for this application: highly oxidized metal for maximum energy storage capacity and a substantial carbonaceous coating and CNT network for high conductivity and thus improved cell stability. This highlights the potential for continuous production of oxidized core particles $(\Phi=0.004)$ without adversely affecting the CNTs.

X-ray Photoelectron Spectroscopy (XPS) shown in Figure 4d-f of iron, aluminum, and oxygen respectively confirm the presence of oxides. Particularly, the iron is well-oxidized as shown by the spectra from 707-709 eV, indicating that elemental iron is not present.(41) Moreover, the peak at $711.0 \mathrm{eV}$ is characteristic of $\mathrm{Fe}^{3+}$, an ionic state which is present in both $\mathrm{Fe}_{2} \mathrm{O}_{3}$ and $\mathrm{Fe}_{3} \mathrm{O}_{4}$. (42) The satellite peak at $719.6 \mathrm{eV}$ is also characteristic of $\mathrm{Fe}^{3+}$, particularly $\mathrm{Fe}_{2} \mathrm{O}_{3}$, and the peaks from the $\mathrm{Fe} 2 \mathrm{p}_{1 / 2}$ orbital located at 724.4 and $733.2 \mathrm{eV}$ support the claim that the iron is nearly fully oxidized.(43) The additional width of both the primary Fe $2 p_{3 / 2}$ and Fe $2 p_{1 / 2}$ profiles (best fit with second peaks 
at 713.7 and $727.3 \mathrm{eV}$ respectively) may indicate the presence of $\mathrm{Fe}^{2+}$, likely in the form of $\mathrm{Fe}_{3} \mathrm{O}_{4}$, since the other $\mathrm{Fe}^{2+}$ oxide, $\mathrm{FeO}$, is unstable below $575^{\circ} \mathrm{C}$.(44) The oxygen 1 s scan is best fit with peaks at 529.5, 530.6 and $531.9 \mathrm{eV}$ : typical values for metal oxides. $(42,45,46)$ It therefore seems likely that the iron in these particles is primarily in the form of $\mathrm{Fe}_{2} \mathrm{O}_{3}$ since the profile best matches the fully oxidized $\mathrm{Fe}^{3+}$ state while some portion of $\mathrm{Fe}_{3} \mathrm{O}_{4}$ exists as well (attributed to the weaker evidence of $\mathrm{Fe}^{2+}$ ). Aluminum scans show a profile best fit with two peaks, located at 72.7 and $73.4 \mathrm{eV}$. These are most likely associated with $\mathrm{Al}_{2} \mathrm{O}_{3}$.(47) Aluminum is a very reactive metal however, and will certainly form an oxide on its surface during annealing so the presence of $\mathrm{Al}_{2} \mathrm{O}_{3}$ is highly probable even at room temperatures. This oxide layer is self-limiting so it is conceivable that some elemental aluminum exists below the surface. However since the primary particles have $d_{\mathrm{pp}}<20 \mathrm{~nm}$, the majority of their volume exists within several nanometres of the surface, so most of the aluminum should exist as an oxide.

\section{Electrochemical performance}

Figure 5a shows the discharge-charge voltage profiles for the first two cycles at $0.1 \mathrm{C}$ where the characteristic voltage plateau for iron oxide around $0.75 \mathrm{~V}$ is observed.(48-51) The capacity was calculated based on the mass fraction of metal oxide $(48.4 \%$ of the total mass i.e. $\Psi=0.516$ according to the TGA). The first discharge capacity is approximately $1610 \mathrm{mAh} / \mathrm{g}$ and the reversible charge capacity is approximately $870 \mathrm{mAh} / \mathrm{g}$. Given that the metal oxide is comprised of both iron and aluminum oxide (approximately $75 \%$ of the metal oxide mass is attributed to iron oxide given a $2 \mathrm{Fe}: 1 \mathrm{Al}$ molar ratio) the capacity could

a)

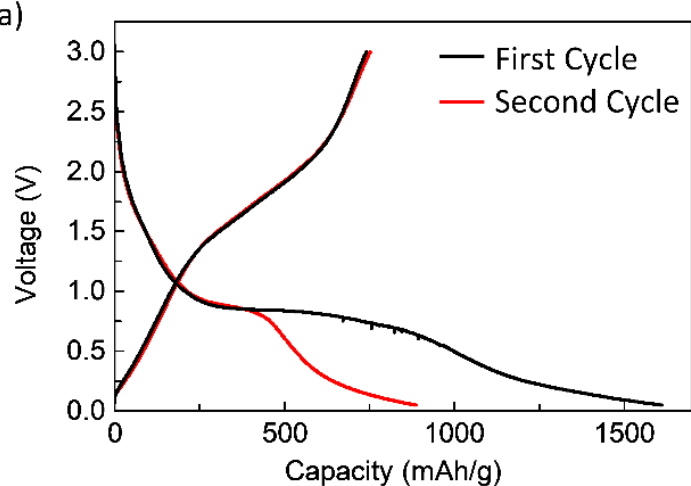

c)

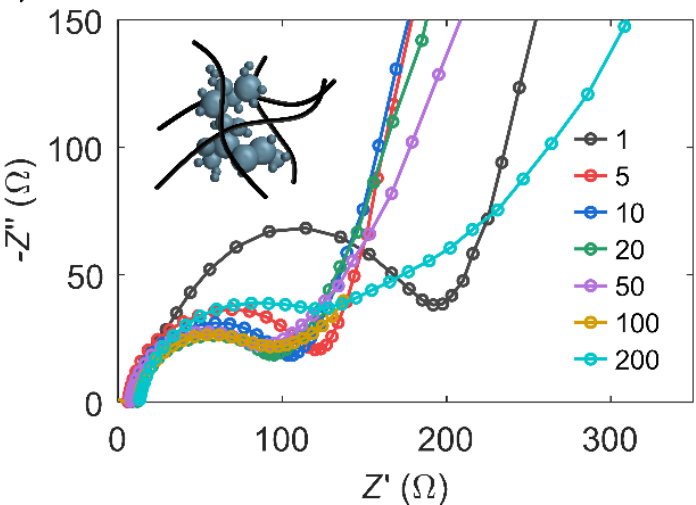

be scaled further to present results on the basis of iron oxide mass. In this case, the resulting capacity is somewhat higher than iron oxide's theoretical capacity of around $1000 \mathrm{mAh} / \mathrm{g}$. It is not likely that aluminum is contributing to the storage capacity of the material since it is well-oxidized and most of the aluminum will exist as aluminum oxide (which will only be reduced at a voltage higher than the cycling voltage of this cell) particularly on the particle surface, as discussed in the preceding XPS results. Instead, any additional capacity beyond that of iron oxide is likely due to the carbonaceous coating present on many of the larger metal oxide particles. Additionally, the CNTs themselves may also be contributing some storage potential, and this effect has been demonstrated previously.(52) A reduction plateau in Figure 5a around $0.75 \mathrm{~V}$ (corresponding to $\mathrm{Li}$ insertion into $\mathrm{Fe}_{2} \mathrm{O}_{3}$ and $\mathrm{Li}_{2} \mathrm{O}$ formation) can be observed as well as sloped delithiation curve (reoxidation of iron metal, $\mathrm{Fe}^{0}$ to $\mathrm{Fe}^{3+}$ ). This can also be observed using the $\mathrm{CV}$ plot in the supporting information. Therefore, although the overall capacity of this material may be a combination of storage mechanisms from multiple components, the majority of the capacity is indeed related to the iron oxide. The primary function of the CNTs is to act as conductive pathways between the metal oxide particles and as a result no conductive additive is necessary. This simplifies the anode construction process since only two components are now required.
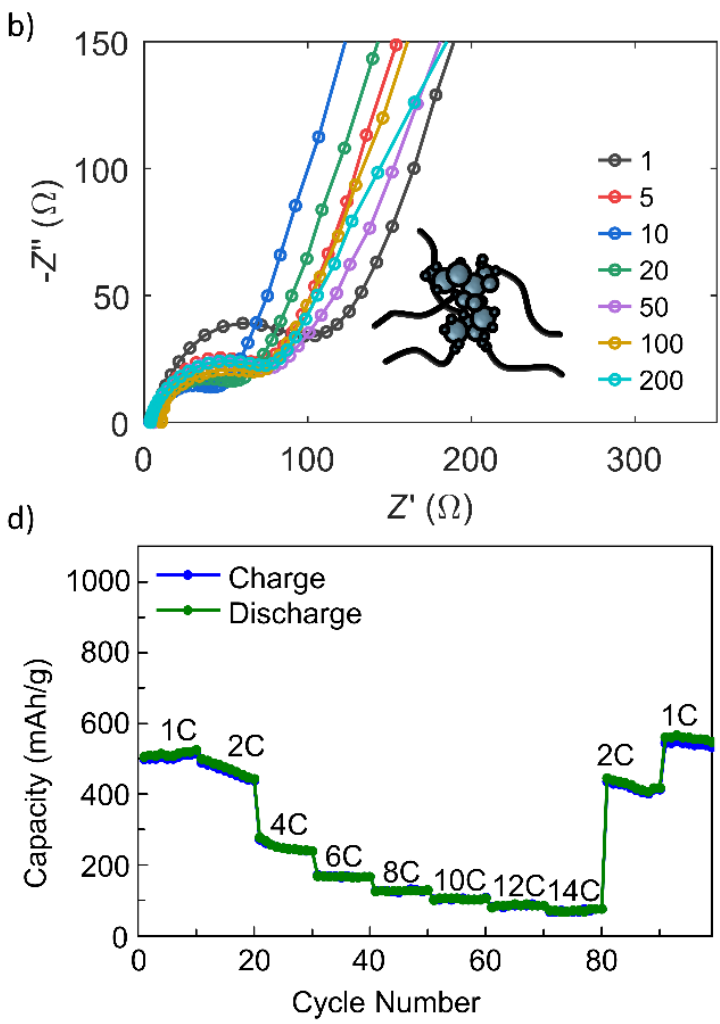

Figure 5: (a) First and second discharge and charge casted electrodes at $0.1 \mathrm{C}$, (b) electrochemical impedance spectra for metal oxide particles with CNTs grown insitu after various cycles, and (c) electrochemical impedance spectra for metal oxide particles externally mixed with pre-fabricated CNTs after various cycles, and (d) specific capacities for rates from 1 - $14 \mathrm{C}$. 
In fact, the carbon coating and CNT improvement to electrical conductivity is corroborated upon observation of Figure $5 \mathrm{~b}$ and c. Figure $5 b$ shows a Nyquist plot from electrochemical impedance spectroscopy (EIS) data for the metal oxide material with carbon coating and CNTs grown in-situ from the particle surfaces at various cycles ranging from 1 to 200. Conversely, Figure $5 c$ shows EIS data for the same metal oxide cores but rather than in-situ carbon growth the cores were mixed ex-situ with pre-fabricated CNTs. Experimental details for cycling and EIS are presented in the methods section. The semicircle in the Nyquist plot is related to charge transfer resistance in the electrode layer. Because mass loadings were identical in both electrodes, the smaller semicircular profile seen for the in-situ carbon growth indicate better electron conduction compared with the ex-situ metal oxide and CNT mixture electrode. With increasing cycles, both electrodes show decreasing charge transfer resistance. The in-situ mixture shows little variation in charge transfer resistance up to $200^{\text {th }}$ cycle, but the ex-situ mixture shows an abrupt increase in charge transfer resistance at the $200^{\text {th }}$ cycle. The conclusion can therefore be made that the in-situ CNT growth directly from the aggregate surface and carbon coating growth presented in this process produces a material with improved electrical conductivity when compared to externally mixing a conductive additive.

For a rate of $1 \mathrm{C}$ on the rate-varying coin cell, a reversible specific capacity of around $500 \mathrm{mAh} / \mathrm{g}$ could be achieved (Figure $5 d)$. For higher rates up to $14 \mathrm{C}$ a drop in capacity was observed, which could be due to poor ion conduction at these high current densities or non-ideal contact between the individual CNTs resulting in less active material participating in the reaction. This could be improved by calendering the electrodes. The fluctuation in capacity between the lower rates could be explained by temperature fluctuations during the electrochemical measurement. Despite what may have been imperfect contact, capacity recovery at lower rates after cycling at higher rates is excellent, with the material performing equal to or better than the initial cycles at $1 \mathrm{C}$. Long-term behavior is shown in the supporting information. The capacity increases slightly over time from what could be due to inactive material becoming exposed from the repeated volume change during the cycling. The same phenomenon is likely responsible for the capacity increase at $1 \mathrm{C}$ in the rate test. Electrolyte additives such as fluoroethylene carbonate (FEC) may be able to improve the cell's reversibility.

While this work demonstrates metal oxide-CNT hybrid material as an application of this process, the significant advantage is the efficient synthesis method for hierarchical metal and carbonbased materials. Thermal plasmas process raw precursors at a high rate, synthesizing final products in approximately ten seconds, compared to hours or even days for wet chemistry approaches. Further, the use of low-grade precursors leads to efficient processing costs and a potential dramatic reduction in final material cost when compared to the same material produced from pre-existing components. Specifically, compared to nanopowders, the coarse metal powder used here is $\sim 1 / 100^{\text {th }}$ the cost, and the carbon-containing gas (e.g. acetylene), reduces the cost by hundreds to several thousand times compared to pre-fabricated CNTs. The resulting high rate synthesis allows for fast screening of material systems with the potential for industrialization of these materials.

The overall performance of the metal oxide-CNT material demonstrates long term stability and robust capacity recovery at high rates. The synthesis process itself is highly attractive for high production rates since it is simple, inexpensive, continuous, and fast. Multiple opportunities for optimization including further calendering, electrolyte optimization and pre-lithiation that could further improve the performance of this anode material performance. The unique hierarchical architecture, strong battery performance metrics and high-throughput production result in a holistically attractive material for lithium ion battery anodes.

\section{Conclusion}

A plasma-based process for fast, facile, and inexpensive synthesis of a metal oxide - carbon nanotube composite active material for conversion anodes in lithium ion cells has been presented. Largely due to the exceptionally high temperature of the plasma, the active material can be synthesized in a matter of seconds using inexpensive and readily available raw precursor materials which are orders of magnitude less expensive than their pre-fabricated counterparts. This is the first demonstration that high energy density thermal plasma systems can be controlled for hierarchical, multicomponent material production for energy storage applications. The resulting composite material is formed of multi-scale structures beginning with metal oxide primary particles which agglomerate while suspended in the gas phase to form larger metal oxide aggregates. CNTs are then grown from the primary particles within the aggregates (while a carbonaceous coating is also formed on many of the primary particles) and the $\mathrm{CNT} /$ metal oxide particles are collected as a powder. The carbonaceous coating increases the short-range (intraaggregate) electrical conductivity while the CNTs enhance the long-range (inter-aggregate) conductivity. An ex-situ annealing step was performed to ensure the metal was fully oxidized. The mass-mobility exponent of the aggregate particles was determined to be 2.31 , indicating an open aggregate structure for lithium ion diffusion. The primary particles within the aggregates were characterized with on-line aerosol methods allowing for real-time optimization. The primary particle diameter scaled with aggregate diameter and the populationaveraged primary particle diameter was $13.4 \mathrm{~nm}$, which agrees well with the $11.28 \pm 6.85 \mathrm{~nm}$ TEM analysis. The final material displayed a reversible capacity of $870 \mathrm{mAh} / \mathrm{g}$ on a metal oxide mass basis. If scaled for the mass of iron oxide, the capacity exceeds the theoretical capacity of iron oxide, meaning that other components of this material, most likely the carbon coating or CNTs contribute to energy storage as well. Long term cycling showed capacity increased which could be due to exposure of new active material from repeated volume expansion. Stability could be enhanced by further calendering. 
The material shows resistance to degradation from high rate cycling and robust recovery. This work demonstrates that high performance anodes can be synthesized from this remarkably fast, simple, and scalable continuous throughput process.

\section{Experimental}

The experimental configuration is displayed in Figure 1i with a more comprehensive schematic in Figure S2 in the supporting information. Energy is supplied to the process with a Sairem GMP $60 \mathrm{~K}$ microwave plasma system, operating with a frequency of $2.45 \mathrm{GHz}$. Input power can range from $600 \mathrm{~W}$ to $6.0 \mathrm{~kW}$ with typical powers in this work of $1.5 \mathrm{~kW}$. The plasma system is equipped with a 3-stub tuner and sliding short circuit which serve to condition the microwave field such that the maximum amplitude is located in the centre of the work tube and that the amount of power reflected back to the magnetron is as low as possible. The waveguide is located between the 3stub tuner and the sliding short circuit, and contains the quartz work tube ( $500 \mathrm{~mm}$ length, $30 \mathrm{~mm}$ O.D., $23.5 \mathrm{~mm}$ I.D.). Nitrogen is used as the plasma gas ( 9 slpm, BOC, $99.998 \%$ purity).

A powder feeder (Lambda Doser, Lambda Laboratory Instruments) is connected to the inlet of the work tube. Several components of the powder feeder have been replaced with customized 3D printed versions to improve the stability of the feed rate. Powder is delivered to the plasma system in the form of elemental metals (i.e. iron and aluminum: Goodfellow, max $60 \mu \mathrm{m}, 99.0 \%$ and $99.9 \%$ purity respectively) at a rate of approximately $30 \mathrm{mg} / \mathrm{min}$.

Downstream of the plasma, the material is passed into a tube furnace (alumina tube, $500 \mathrm{~mm}$ total length, $300 \mathrm{~mm}$ heated section, $30 \mathrm{~mm}$ O.D., $23 \mathrm{~mm} \mathrm{I.D.)} \mathrm{at} 830^{\circ} \mathrm{C}$. A total flow rate of $1.7 \mathrm{slpm}$ is sent through the furnace, of which approximately 1.5 slpm is gas from the plasma (remainder of plasma gas vented to extraction), $200 \mathrm{sccm}$ is hydrogen (BOC, 99.999\%), and a small amount $(10-20 \mathrm{sccm})$ is acetylene (BOC, 98.5\%). CNTs and a carbonaceous coating are grown on the core particles in the furnace during the residence time of several seconds then the material is collected on PTFE filters.

The ability to vaporize metal powders at any appreciable rate in a wide range of gas mixtures is a feature and advantage that is unique to plasma processes and is a large contributing factor towards the widespread use of plasmas for large-scale nanopowder production. The mechanisms of this particular process are examined in detail in Figure 1i. Relatively large elemental metal powder particles $(\sim 60 \mu \mathrm{m})$ are fed into the plasma where they are vaporized from the high temperature $\left(>2500^{\circ} \mathrm{C}\right)$. Downstream of the plasma where the temperature begins to decrease, supersaturation of the metal vapours is reached, and homogeneous nucleation of metal nanoparticles occurs. The particles increase in size from surface growth and agglomerate into fractal-like aggregates with mobilityequivalent diameters between approximately $20 \mathrm{~nm}$ and 200 $\mathrm{nm}$.
As the particles enter the growth furnace, CNTs are grown from catalyst sites of reduced, elemental iron present on the core particles' surfaces. Multiple CNTs can be grown radially from each particle, resulting in the "sea urchin-like" morphology. Finally, an ex-situ oxidation step is performed to complete the synthesis process.

\section{Electron Microscopy}

Both transmission electron microscopy (TEM) and scanning electron microscopy (SEM) were used to analyse the morphology of the CNT-metal oxide composite material. For TEM, the samples were prepared in dry conditions by spreading the samples as a powder onto 400 mesh copper grids with a holey carbon film (Agar Scientific). High-resolution TEM (HRTEM) images were obtained using a Tecnai F20 system at $200 \mathrm{kV}$ with a high brightness field emission gun (FEG). SEM samples were prepared on single crystal silicon substrates. Particles were either deposited with a thermophoretic sampler or by spreading filter-collected dry powder over the substrate, applying a drop of ethanol and air drying. SEM images were obtained using a Leo Variable pressure SEM with an accelerating voltage of $2.49 \mathrm{kV}$ and a working distance of approximately 5 $\mathrm{mm}$.

\section{Aggregate size distribution measurements}

The size distribution of the aggregated particles both with and without the CNTs can be characterized using a Scanning Mobility Particle Spectrometer (SMPS) which is comprised of a Differential Mobility Analyzer (DMA) and Condensation Particle Counter (CPC). Particles are first given an electric charge using a radioactive or $\mathrm{x}$-ray charger and are then classified in the DMA by electrical mobility or more intuitively, their drag to charge ratio. Particles are passed through the annular region between two concentric cylinders while a negative voltage is applied to the inner cylinder. Positively charged particles are attracted to the inner cylinder but the rate at which they migrate towards this cylinder is limited by their aerodynamic drag. Particles with the correct charge to drag ratio reach the inner cylinder exactly at its end and are "classified".

As the DMA sweeps through various electrical mobilities the CPC counts the number of particles at each mobility setting. Mobility is then converted to a particle size (mobility-equivalent diameter) and a number-based particle size distribution can be created. For this work, a 3081 series DMA (TSI Inc.) and 3022A series CPC (TSI Inc.) were used. For the core size distribution, the CPC was set to "high flow" mode (1.5 lpm) and the DMA sheath flow was $15 \mathrm{lpm}$, resulting in a resolution of 10 (i.e. the full width half maximum of the transfer function of the DMA was one tenth of its set point). For the size distribution after CNT growth the CPC was set to "low flow" mode $(0.3 \mathrm{lpm})$ and the DMA sheath was $3 \mathrm{lpm}$, preserving the resolution of 10 . A dilution ratio of 11 was used for these measurements, but the results presented here have been corrected for this ratio and represent the true volumetric number concentrations. Each data set was then fit with the summation of two lognormal distributions, while the overall statistics including geometric 
mean, geometric standard deviation, and total particle concentration are presented in Figure $3 a$ and in the text.

\section{Aggregate mass measurement}

Particle mass can be measured with a Centrifugal Particle Mass Analyzer (CPMA), which classifies particles by mass to charge ratio.(53) Similar to an SMPS, the CPMA can be stepped through various mass setpoints while a CPC measures the concentration at each mass. A number-based mass distribution can then be generated. Furthermore, if particles of a specific mobility equivalent diameter are preselected, a CPMA scan can give the mass of these particles. Performing this measurement at several sizes throughout the total particle distribution can allow the mass mobility relation to be created and the mass-mobility exponent can be extracted.

\section{Estimation of primary particle size and number per aggregate} The average primary particle diameter within an aggregate and the average number of primaries per aggregate can be estimated if the aggregate's mass and mobility-equivalent diameter are known. From Eggersdorfer et al.(33), the average primary diameter and number within a given aggregate are (respectively):

$$
d_{\mathrm{pp}}=\left(\frac{\pi k_{a}}{6 v} d_{m}^{2 D_{\alpha}}\right)^{\frac{1}{2 D_{\alpha}-3}}
$$

and

$$
n_{\mathrm{pp}}=\frac{6 v}{\pi d_{p p}{ }^{3}}
$$

$d_{p p}$ is the average primary particle diameter, $d_{m}$ is mobilityequivalent diameter, $n_{p p}$ is the average number of primary particles per aggregate, $k_{a}$ and $D_{\alpha}$ are empirically-determined constants, and $v$ is the solid volume of the aggregate, equal to

$$
v=\frac{m}{\rho}
$$

where $m$ is particle mass and $\rho$ is the particle's bulk density. $k_{a}$ and $D_{\alpha}$ were determined by Eggersdorfer et al.(33) as 1.0 and 1.07 respectively from work with $\mathrm{ZrO}_{2}$ aggregates, while assuming a well-mixed primary particle sample and minimal primary particle shielding within the aggregate (i.e. all particles are exposed to the surrounding gas). The average primary particle diameter and number per aggregate can be used in conjunction with the aggregate size distribution to calculate the population-averaged primary particle diameter as follows:

$$
\overline{d_{\mathrm{pp}}}=\frac{\sum\left(\frac{\mathrm{d} N}{\mathrm{~d} \log d_{\mathrm{m}}}\right)\left(\mathrm{d} \log d_{\mathrm{m}}\right) n_{\mathrm{pp}} d_{\mathrm{pp}}}{\sum\left(\frac{\mathrm{d} N}{\mathrm{~d} \log d_{\mathrm{m}}}\right)\left(\operatorname{dlog} d_{\mathrm{m}}\right) n_{\mathrm{pp}}} .
$$

\section{Mass concentration}

The mass distribution is first determined by multiplying the number-based size distribution by the particle mass-mobility function:

$$
\begin{gathered}
\frac{\mathrm{d} M}{\operatorname{dlog} d_{\mathrm{m}}}=m\left(\frac{\mathrm{d} N}{\operatorname{dlog} d_{\mathrm{m}}}\right)= \\
C d_{\mathrm{m}}{ }^{D_{\mathrm{m}}}\left(\frac{\mathrm{d} N}{\operatorname{dlog} d_{\mathrm{m}}}\right) .
\end{gathered}
$$

Here, $\mathrm{d} M / \mathrm{d} \log d_{\mathrm{m}}$ is the mass concentration of a given particle size bin, normalized by bin width. Total mass concentration $M$ can be calculated by summing the distribution:

$$
\begin{gathered}
M=\sum \frac{\mathrm{d} M}{\operatorname{dlog} d_{\mathrm{m}}}\left(\operatorname{dlog} d_{\mathrm{m}}\right)= \\
\sum C d_{\mathrm{m}}^{D_{\mathrm{m}}}\left(\frac{\mathrm{d} N}{\operatorname{dlog} d_{\mathrm{m}}}\right)\left(\operatorname{dlog} d_{\mathrm{m}}\right) .
\end{gathered}
$$

\section{Raman Spectrometry}

Raman spectra were collected on a Horiba Explora Plus using a $638 \mathrm{~nm}$ laser. While a radial breathing mode was observed which indicates the presence of metallic single-walled CNTs, other single-walled CNT chiralities may also have been synthesized which are not resonant with the $638 \mathrm{~nm}$ laser i.e. points that exist at a different $y$-axis position in Figure $4 b$. Raman signals were also recorded using a $532 \mathrm{~nm}$ laser; however the reflection of this wavelength off the metal oxide cores produced a broad background spectrum and it was not possible to resolve the CNT signal.

\section{Electrochemical tests of half coin cells}

The electrochemical properties of the compounds were evaluated in 2032 coin cells containing metallic lithium foils as cathodes (half-cells). For the anodes, a slurry was prepared containing $90 \mathrm{wt} \%$ active material composite and $10 \mathrm{wt} \%$ polyvinylidene difluoride (PVDF) binder in N-methyl-2pyrrolidone (NMP). Since the active material already contained highly conductive CNTs, it was not necessary to introduce any other conductive additives to the slurry. The slurry was cast onto etched copper. The electrodes were dried first in air and then under vacuum at $60^{\circ} \mathrm{C}$ for 12 hours before being cut to size and weighed in an argon-filled glovebox. The typical loading was $0.5 \mathrm{mg} / \mathrm{cm}^{2}$. 1.0 M LiPF 6 EC/EMC = 50/50 (v/v) electrolyte and Celgard separators were used in the coin cells. Galvanostatic cycling experiments at room temperature were carried out with Biologic VMP3 and Lanhe potentiostats/galvanostats. The cells were cycled in between $0.05-3 \mathrm{~V}$ and C-Rates from 0.1 to $14 \mathrm{C}$. Electrochemical impedance spectroscopy $(1000$ to $0.05 \mathrm{~Hz}, 5$ $\mathrm{mV}$ amplitude) was conducted using Biologic VMP3.

\section{Conflicts of interest}

There are no conflicts to declare.

\section{Acknowledgements}

Funding for this project was provided by EPSRC grants EP/M015211/1 and EP/L016087/1. Waveguide 3D model in Figure $1 \mathrm{i}$ courtesy of Sairem. 


\section{Notes and references}

1. Ban C, Wu Z, Gillaspie DT, Chen L, Yan F, Blackburn JL, et al. Nanostructured Fe3O4/SWNT electrode: Binder-free and high-rate Li-ion anode. Adv Mater. 2010;22(20):145-9.

2. Jia X, Chen Z, Cui X, Peng Y, Wang X, Wang G, et al. Building Robust Architectures of Carbon and Metal Oxide Nanocrystals toward High-Performance Anodes for Lithium-Ion Batteries. ACS Nano. 2012;6(11):9911-9.

3. Choi SH, Lee J, Kang YC. Perforated Metal Oxide - Carbon Nanotube Composite Microspheres with Enhanced Lithium-Ion Storage Properties. ACS Nano. 2015;(10):10173-85.

4. Huang G, Zhang F, Du X, Qin Y, Yin D, Wang L. Metal Organic Frameworks Route to in Situ Insertion of Multiwalled Carbon Nanotubes in Co 304 Polyhedra as Anode Materials for Lithium-Ion Batteries. ACS Nano. 2015;9(2):1592-9.

5. Sun $X, X u Y$, Ding $P$, Chen $G$, Zheng $X$, Zhang $R$, et al. The composite sphere of manganese oxide and carbon nanotubes as a prospective anode material for lithium-ion batteries. J Power Sources [Internet]. 2014;255(28):163-9. Available from: http://dx.doi.org/10.1016/j.jpowsour.2013.12.106

6. Yue J, Gu X, Jiang X, Chen L, Wang N, Yang J, et al. Coaxial Manganese Dioxide @ N-doped Carbon Nanotubes as Superior Anodes for Lithium Ion Batteries. Electrochim Acta [Internet]. 2015;182:676-81. Available from: http://dx.doi.org/10.1016/j.electacta.2015.09.150

7. Yang $T$, Zhang $W$, Li L, Jin B, Jin E, Jeong S, et al. In-situ synthesized ZnFe 204 firmly anchored to the surface of MWCNTs as a long-life anode material with high lithium storage performance. Appl Surf Sci [Internet].

2017;425:978-87. Available from:

http://dx.doi.org/10.1016/j.apsusc.2017.07.152

8. Sun LY, Yang L, Li J, Narayan RL, Ning XH. Superior full-cel cycling and rate performance achieved by carbon coated hollow Fe3O4 nanoellipsoids for lithium ion battery. Electrochim Acta. 2018;288:71-81.

9. Zhong $\mathrm{G}, \mathrm{Yu}$ J, Zhuang $\mathrm{P}$, Jin M, Fu Y, Ma X. Ultralong MnO@C nanowires with internal voids anchored between graphene as a robust high performance anode for flexible Li-Ion battery. Electrochim Acta [Internet]. 2019;296:27682. Available from:

https://linkinghub.elsevier.com/retrieve/pii/S0013468618 322096

10. Li W, An C, Guo H, Sun J, Wang M, Li Y, et al. In Situ Synthesis of 1D Mesoporous MnO@C Nanorods for High Performance Li-Ion Batteries. ACS Sustain Chem Eng [Internet]. 2019;7:139-46. Available from: http://pubs.acs.org/doi/10.1021/acssuschemeng.8b01782

11. Johnson Matthey Technology Review. Vol. 59, Johnson Matthey Technology Review. 2015.

12. Kim SH, Wang C, Zachariah MR. Aerosol formation of SeaUrchin-like nanostructures of carbon nanotubes on bimetallic nanocomposite particles. J Nanoparticle Res. 2010;13(1):139-46.

13. De La Verpilliere J, JessI S, Saeed K, Ducati C, De Volder M,
Boies A. Continuous flow chemical vapour deposition of carbon nanotube sea urchins. Nanoscale [Internet]. 2018;10(16):7780-91. Available from: http://dx.doi.org/10.1039/c7nr09534a

14. Ru Q, Song X, Mo Y, Guo L, Hu S. Carbon nanotubes modi fi ed for $\mathrm{ZnCo} 2 \mathrm{O} 4$ with a novel porous polyhedral structure as anodes for lithium ion batteries with improved performances. J Alloys Compd [Internet]. 2015;654:58692. Available from:

http://dx.doi.org/10.1016/j.jallcom.2015.09.105

15. Guan C, Liu J, Wang Y, Mao L, Fan Z, Shen Z, et al. Iron Oxide-Decorated Carbon for Supercapacitor Anodes with Ultrahigh Energy Density and Outstanding Cycling Stability. ACS Nano. 2015;(5):5198-207.

16. Lou F, Zhou H, Tran D, Melands $\varnothing$ E. Coaxial Carbon / Metal Oxide / Aligned Carbon Nanotube Arrays as HighPerformance Anodes for Lithium Ion Batteries. ChemSusChem. 2014;1335-46.

17. Li Y, Ye D, Liu W, Shi B, Guo R, Pei H, et al. A threedimensional core-shell nanostructured composite of polypyrrole wrapped $\mathrm{MnO} 2$ / reduced graphene oxide / carbon nanotube for high performance lithium ion batteries. J Colloid Interface Sci [Internet]. 2017;493:2418. Available from: http://dx.doi.org/10.1016/j.jcis.2017.01.008

18. Ren J, Yang J, Abouimrane A, Wang D, Amine K. SnO 2 nanocrystals deposited on multiwalled carbon nanotubes with superior stability as anode material for Li-ion batteries. J Power Sources [Internet]. 2011;196(20):87015. Available from: http://dx.doi.org/10.1016/j.jpowsour.2011.06.036

19. Wang J, Fang F, Yuan T, Yang J, Chen L, Yao C, et al. ThreeDimensional Graphene / Single-Walled Carbon Nanotube Aerogel Anchored with SnO 2 Nanoparticles for High Performance Lithium Storage. ACS Appl Mater Interfaces. 2017;9:3544-53.

20. Kose $\mathrm{H}$, Karaal S, Aydin A, Akbulut H. A facile synthesis of zinc oxide / multiwalled carbon nanotube nanocomposite lithium ion battery anodes by sol-gel method. J Power Sources. 2015;295:235-45.

21. Wu J, Yin W, Liu W, Guo P, Liu G, Liu X, et al. High performance $\mathrm{NiO}$ nanosheets anchored on threedimensional nitrogen-doped carbon nanotubes as a binderfree anode for lithium ion batteries. J Mater Chem A Mater energy Sustain [Internet]. 2016;4:10940-7. Available from: http://dx.doi.org/10.1039/C6TA03137D

22. Li S, Liu Y, Guo P, Wang C. Self-Climbed Amorphous Carbon Nanotubes Filled with Transition Metal Oxide Nanoparticles for Large Rate and Long Lifespan Anode Materials in Lithium Ion Batteries. ACS Appl Mater Interfaces. 2017;9:26818-25.

23. Wang L, Zhuo L, Cheng H, Zhang C, Zhao F. Porous carbon nanotubes decorated with nanosized cobalt ferrite as anode materials for high-performance lithium-ion batteries. J Power Sources [Internet]. 2015;283:289-99. Available from: http://dx.doi.org/10.1016/j.jpowsour.2015.02.138 
24. Palmieri A, Kash R, Yazdani S, Pettes M, Mustain WE. High Performance Bi-Metallic Manganese Cobalt Oxide / Carbon Nanotube Li-ion Battery Anodes. Electrochim Acta. 2016;213:620-5.

25. Yao W, Xu J, Wang J, Luo J, Shi Q, Zhang Q. Chemically Integrated Multiwalled Carbon Nanotubes/Zinc Manganate Nanocrystals as Ultralong-Life Anode Materials for LithiumIon Batteries. ACS Sustain Chem Eng. 2015;3:2170-7.

26. Seo J-H, Hong B-G. Thermal Plasma Synthesis of Nano-sized Powders. Nucl Eng Technol [Internet]. 2012;44(1):9-20. Available from: http://iupac.org/publications/pac/70/2/0485/

27. Smiljanic O, Stansfield BL, Dodelet JP, Serventi A, Désilets $S$ Gas-phase synthesis of SWNT by an atmospheric pressure plasma jet. Chem Phys Lett. 2002;356:189-93.

28. Zajíčková L, Synek P, Jašek O, Eliáš $M$, David B, Buršík J, et al. Synthesis of carbon nanotubes and iron oxide nanoparticles in $\mathrm{MW}$ plasma torch with $\mathrm{Fe}(\mathrm{CO}) 5$ in gas feed. Appl Surf Sci. 2009;255(10):5421-4.

29. Kim KS, Moradian A, Mostaghimi J, Alinejad Y, Shahverdi A, Simard B, et al. Synthesis of single-walled carbon nanotubes by induction thermal plasma. Nano Res. 2009;2(10):800-17.

30. Kim KS, Kingston CT, Ruth D, Barnes M, Simard B. Synthesis of high quality single-walled carbon nanotubes with purity enhancement and diameter control by liquid precursor ArH2 plasma spraying. Chem Eng J [Internet]. 2014;250:33141. Available from:

http://linkinghub.elsevier.com/retrieve/pii/S13858947140 04173

31. Zhang Q, Yu Z, Du P, Su C. Carbon Nanomaterials Used as Conductive Additives in Lithium Ion Batteries. Recent Pat Nanotechnol. 2010;4(2):100-10.

32. Vemury S, Pratsinis SE. Self-preserving size distributions of agglomerates. J Aerosol Sci. 1995;26(2):175-85.

33. Eggersdorfer ML, Gröhn AJ, Sorensen $\mathrm{CM}, \mathrm{Mcmurry} \mathrm{PH}$ Pratsinis SE. Mass-mobility characterization of flame-made ZrO 2 aerosols : Primary particle diameter and extent of aggregation. J Colloid Interface Sci [Internet]. 2012;387(1):12-23. Available from: http://dx.doi.org/10.1016/j.jcis.2012.07.078

34. Kelesidis GA, Furrer FM, Wegner K, Pratsinis SE. Impact of Humidity on Silica Nanoparticle Agglomerate Morphology and Size Distribution. Langmuir. 2018;34(29):8532-41.

35. Svensson CR, Ludvigsson L, Meuller BO, Eggersdorfer ML, Deppert K, Bohgard M, et al. Characteristics of airborne gold aggregates generated by spark discharge and high temperature evaporation furnace: Mass-mobility relationship and surface area. J Aerosol Sci [Internet]. 2015;87:38-52. Available from:

http://dx.doi.org/10.1016/j.jaerosci.2015.05.004

36. Stein $\mathrm{M}$, Kiesler D, Kruis FE. Adjustment and online determination of primary particle size in transferred arc synthesis of copper nanoparticles. Aerosol Sci Technol. 2013;47(11):1276-84.

37. Peled E, Menkin S. Review-SEI: Past, Present and Future. J Electrochem Soc [Internet]. 2017;164(7):A1703-19.
Available from:

http://jes.ecsdl.org/lookup/doi/10.1149/2.1441707jes

38. Kharissova O V., Kharisov BI. Variations of interlayer spacing in carbon nanotubes. RSC Adv [Internet]. 2014;4(58):30807-15. Available from:

http://dx.doi.org/10.1039/C4RA04201H

39. Dresselhaus MS, Dresselhaus G, Saito R, Jorio A. Raman spectroscopy of carbon nanotubes. Phys Rep.

2005;409(2):47-99.

40. Thomsen C, Reich S. Raman scattering in carbon nanotubes. Light Scatt Solid IX [Internet]. 2007;108:115208. Available from: http://link.springer.com/chapter/10.1007/978-3-54034436-0_3

41. Mathieu $\mathrm{H}$, Landolt $\mathrm{D}$. An investigation of thin oxide films thermally grown in situ on $\mathrm{Fe} 24 \mathrm{Cr}$ and $\mathrm{Fe} 24 \mathrm{Cr} 11 \mathrm{Mo}$ by auger electron spectroscopy and $\mathrm{X}$-ray photoelectron spectroscopy. Corros Sci. 1986;26(7):547-59.

42. Grosvenor AP, Kobe BA, Biesinger MC, McIntyre NS. Investigation of multiplet splitting of Fe $2 p$ XPS spectra and bonding in iron compounds. Surf Interface Anal. 2004;36(12):1564-74.

43. Wilson D, Langell MA. XPS analysis of oleylamine/oleic acid capped $\mathrm{Fe} 3 \mathrm{O} 4$ nanoparticles as a function of temperature. Appl Surf Sci [Internet]. 2014;303:6-13. Available from: http://dx.doi.org/10.1016/j.apsusc.2014.02.006

44. Greenwood N, Earnshaw A. Chemsitry of the Elements. 2nd ed. Butterworth-Heinemann; 1997.

45. Dupin JC, Gonbeau D, Vinatier P, Levasseur A. Systematic XPS studies of metal oxides, hydroxides and peroxides. Phys Chem Chem Phys. 2000;2(6):1319-24.

46. Yamashita T, Hayes P. Analysis of XPS spectra of Fe2+ and $\mathrm{Fe} 3+$ ions in oxide materials. Appl Surf Sci.

2008;254(8):2441-9.

47. Tago T, Kataoka N, Tanaka H, Kinoshita K, Kishida S. XPS study from a clean surface of Al2O3 single crystals. Procedia Eng [Internet]. 2017;216:175-81. Available from: https://linkinghub.elsevier.com/retrieve/pii/S1877705817 33206X

48. Chen J, Xu L, Li W, Gou X. $\alpha$-Fe2O3 nanotubes in gas sensor and lithium-ion battery applications. Adv Mater. 2005;17(5):582-6.

49. NuLi Y, Zhang P, Guo Z, Liu H. Shape Evolution of $\alpha-\mathrm{Fe} 2 \mathrm{O} 3$ and Its Size-Dependent Electrochemical Properties for Lithium-Ion Batteries. J Electrochem Soc [Internet]. 2008;155(3):A196. Available from: http://jes.ecsdl.org/cgi/doi/10.1149/1.2826278

50. Kim HS, Piao Y, Kang SH, Hyeon T, Sung Y-E. Uniform hematite nanocapsules based on an anode material for lithium ion batteries. Electrochem commun [Internet]. 2010;12(3):382-5. Available from: http://dx.doi.org/10.1016/j.elecom.2009.12.040

51. Wang B, Chen JS, Wu H Bin, Wang Z, Lou XW. Quasiemulsion-templated formation of $\alpha$-Fe2O3 hollow spheres with enhanced lithium storage properties. J Am Chem Soc. 2011;133:17146-8.

52. Raji ARO, Villegas Salvatierra R, Kim ND, Fan X, Li Y, Silva 
GAL, et al. Lithium Batteries with Nearly Maximum Metal Storage. ACS Nano. 2017;11(6):6362-9.

53. Olfert JS, Collings N. New method for particle mass classification - The Couette centrifugal particle mass analyzer. J Aerosol Sci. 2005;36(11):1338-52. 